ORIGINAL ARTICLE

\title{
Why are babies weaned early? Data from a prospective population based cohort study
}

\author{
C M Wright, K N Parkinson, R F Drewett
}

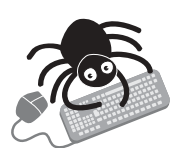

A fuller version of this paper (including tables 1 and 4) appears on the $A D C$ website (www. archdischild.com/ supplemental)

See end of article for authors' affiliations

..................

Correspondence to: Dr C M Wright, Senior Lecturer/Consultant in Community Child Health, PEACH Unit, QMH Tower, Yorkhill Hospitals, Glasgow G3 8SJ, UK; charlotte.wright@clinmed. gla.ac.uk

Accepted 2 December 2003
Arch Dis Child 2004;89:813-816. doi: 10.1136/adc.2003.038448

Background: The recommended age of introduction of solids food to the diet of infants (weaning) has recently been increased in the UK to 6 months, but most babies are still weaned before the age of 4 months.

Aims: To examine what predicts the age of weaning and how this relates to weight gain and morbidity using data from a population based cohort.

Methods: Parents of 923 term infants born in a defined geographical area and recruited shortly after birth were studied prospectively using postal questionnaires, weaning diaries, and routinely collected weights, of whom $707(77 \%)$ returned data on weaning.

Results: The median age of first weaning solids was 3.5 months, with $21 \%$ commencing before 3 months and only $6 \%$ after 4 months of age. Infants progressed quickly to regular solids with few reported difficulties, even when weaned early. Most parents did not perceive professional advice or written materials to be a major influence. The strongest independent predictors of earlier age at weaning were rapid weight gain to age 6 weeks, lower socioeconomic status, the parents' perception that their baby was hungry, and feeding mode. Weight gain after 6 weeks was unrelated to age of weaning. Babies weaned before 3 months, compared to after 4 months, had an increased risk of diarrhoea.

Conclusions: Social factors had some influence on when weaning solids were introduced, but the great majority of all infants were established on solids before the previously recommended age of 4 months, without difficulty. Earlier weaning was associated with an increased rate of minor morbidity.
$\mathrm{T}$ he introduction of complementary foods to the diet (weaning) is a critical nutritional stage in an infant's life and the optimal age for this has been much debated. ${ }^{1}$ The decision when to wean must balance the risk that weaning too early will stress the immature gut, kidneys, and immune system $^{2-5}$ as well as decreasing exposure to the protective effects of breast milk, while weaning too late may result in under-nutrition ${ }^{67}$ and feeding problems. ${ }^{89}$ Until recently the UK officially recommended age was not before 4 months, ${ }^{10}$ but this has recently been revised to 6 months, in line with WHO recommendations. ${ }^{11}$

Despite this advice, successive infant feeding surveys have shown that the majority of UK children continue to be weaned before the age of 4 months. ${ }^{12}$ However, these studies have not generally examined why mothers choose to wean when they do and how infants respond to weaning at different ages. As part of a large scale prospective study of feeding and growth in infancy we set out to explore these issues, as well as the possible associations with growth and morbidity.

\section{METHODS}

The Millennium Baby Study recruited subjects shortly after birth between June 1999 and May 2000. All babies born to Gateshead resident mothers in 34 prespecified weeks were eligible for recruitment. Parents then received questionnaires at 6 weeks, and 4, 8, and 12 months, which all included questions to be completed once complementary solids had been commenced. These asked the age when weaning solids were first given, as well five questions exploring why, answered using a five point Likert scale (strongly agree to strongly disagree). Each questionnaire also asked whether any breast milk was being given at that age, whether the child had seen their family doctor, suffered a cold, diarrhoea, a rash or a chest infection, or been admitted to hospital.

Families were also issued with a parent held record which included a self carbonating weaning diary. Parents completed this when the first five solid feeds were given and returned it with the next questionnaire. For each feed the parents recorded the date, type of food, and how the child responded, as free text; this was subsequently coded as "positive", "negative", or "indifferent".

Parents also transcribed routine baby clinic weights from their parent held record onto each questionnaire; subjects were weighed at a health check at the age of 13 months.

For this analysis, infants born before 37 weeks gestation were excluded, as well as the few infants from minority groups with different weaning customs from the rest of the population.

\section{Analysis}

All weights were converted into standard deviation (SD) scores compared to the UK 1990 growth reference. ${ }^{13}{ }^{14}$ Weight gain was measured using the Thrive Index (TI), a measure of change in weight SD over time, adjusted for regression to the mean. ${ }^{15}$

Sustained Faltering growth was defined as a weight gain (TI) below the 5th centile, persisting across two of four age bands in the first year.

Socioeconomic information collected at recruitment was used to dichotomise families into affluent (homeowner, car owner, and one or more employed parents) and deprived 


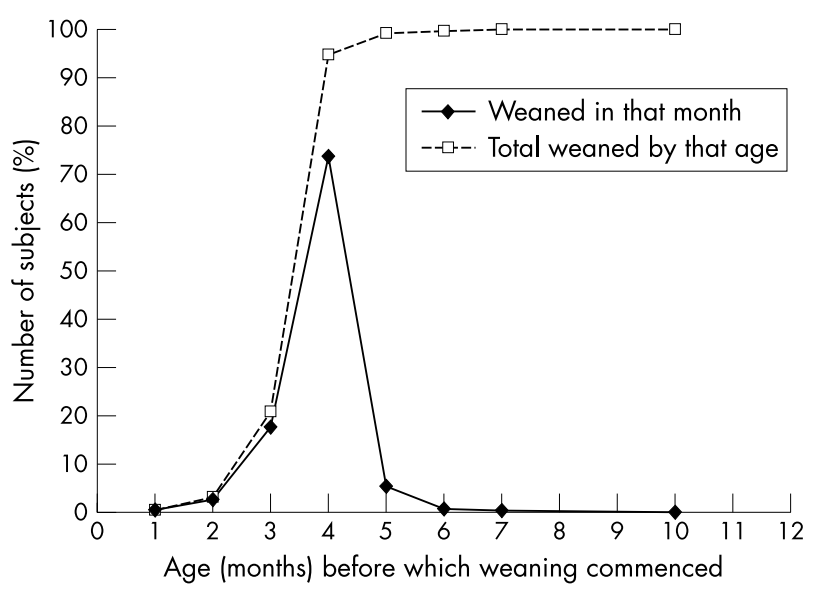

Figure 1 Age at first weaning solids.

(one or more of: rented housing, no car, no employed parent).

\section{RESULTS}

Of the 923 eligible subjects, 707 (77\%) mothers returned questionnaire data on weaning and $604(65 \%)$ completed weaning diaries. Subjects without weaning data were significantly more deprived compared to the whole cohort (table 1; see web version).

The median age at which parents reported first giving solids was 15 weeks (interquartile range $=13-16$; see fig 1 ); $146(21 \%)$ children received solids before 3 months (13 weeks), but only 41 (6\%) after 4 months ( 17.3 weeks). In the weaning diaries, the median age of the first weaning food was 14.6 weeks (13-16 weeks). The geometric mean ( $\pm 1 S D)$ interval from first to fifth offer of a weaning food was 4.7 (2.4 to 9.0) days. Infants weaned before 3 months took slightly longer than those weaned at 3-4 months to progress from lst to 5 th solid feed (geometric mean $=5.0( \pm 1 \mathrm{SD}=2.3$ to 11.1 days) versus 4.5 ( 1.7 to 8.3 ) days; $p=0.08$ ). Those weaned later were no different (4.4 (2.3 to 8.3) days).

The commonest first food offered was baby rice, given by $454(74 \%)$ of mothers; 575 (92\%) were commercially produced foods. The child's reaction to the first food offer was positive for $278(42 \%)$ and negative for 191 (29\%), rising to $470(77 \%)$ responding positively to the fifth offer. There was no effect of age at weaning on the child's reaction.

Weaning before 3 months was associated with male gender, deprivation, and bottle feeding, while continued breast feeding at 4 months and female gender predicted weaning after 4 months (table 2). Earlier weaning was associated with agreeing with the statement "I started solid food because my baby seemed hungry" as well as "my family and friends told me to", while "a book or leaflet suggested I should" was associated with later weaning (table 3).

Heavier babies were on average weaned earlier, but the strongest predictor was weight gain (Thrive Index) from birth to 6 weeks (table 4; see web version). Weight gain after 6 weeks was unrelated to age at weaning. Sustained faltering growth was seen in $30(4.2 \%)$ children within the first year; none of these had been weaned before 3 months, but they were also significantly less likely to have been weaned after 4 months $\left(\chi^{2} \mathrm{p}=0.011\right)$.

Table 2 Demographic predictors of early and late weaning

\begin{tabular}{|c|c|c|c|c|c|}
\hline & \multirow[b]{2}{*}{ Total no. } & \multicolumn{3}{|l|}{ Weaning age } & \multirow[b]{2}{*}{$\mathrm{p} \chi^{2}$} \\
\hline & & $<3 \mathrm{mth}(<13 \mathrm{wk})$ & 3-4 mth & $>4 \mathrm{mth}(>17.3 \mathrm{wk})$ & \\
\hline \multicolumn{6}{|l|}{ Gender } \\
\hline Male & 352 & $58 \%(85)$ & $49 \%(253)$ & $34 \%(14)$ & \multirow[t]{2}{*}{0.004} \\
\hline Female & 355 & $41 \%(61)$ & $51 \%(267)$ & $69 \%(27)$ & \\
\hline \multicolumn{6}{|l|}{ Markers of deprivation } \\
\hline One or more & 303 & $58 \%(85)$ & $39 \%(205)$ & $32 \%(13)$ & \multirow[t]{2}{*}{$<0.001$} \\
\hline None & 404 & $42 \%(61)$ & $61 \%(315)$ & $68 \%(28)$ & \\
\hline \multicolumn{6}{|l|}{ Breast fed } \\
\hline Never & 322 & $60 \%(85)$ & $44 \%(223)$ & $4 \%(14)$ & \multirow[t]{5}{*}{$<0.001$} \\
\hline$<6$ wk & 162 & $22 \%(32)$ & $24 \%(123)$ & $18 \%(7)$ & \\
\hline $6 \mathrm{wk}-4 \mathrm{mth}$ & 71 & $7 \%(10)$ & $12 \%(60)$ & $3 \%(1)$ & \\
\hline$>4 \mathrm{mth}$ & 133 & $11 \%(15)$ & $20 \%(102$ & $42 \%(16)$ & \\
\hline No feeding information & 19 & & & & \\
\hline
\end{tabular}

Table 3 Parents' rating of reasons to commence weaning and the weaning process

\begin{tabular}{|c|c|c|c|c|c|c|}
\hline \multirow[b]{2}{*}{ Question } & \multirow[b]{2}{*}{ Total no. } & \multirow[b]{2}{*}{ Response } & \multicolumn{3}{|l|}{ Weaning age } & \multirow[b]{2}{*}{$\mathbf{p} \chi^{2}$} \\
\hline & & & $\begin{array}{l}\text { Before } 3 \text { mth } \\
(<13 \text { wk) }\end{array}$ & 3-4 mth & $\begin{array}{l}\text { After } 4 \mathrm{mth} \\
(>17.3 \mathrm{wk})\end{array}$ & \\
\hline \multicolumn{7}{|l|}{ I started solid food because: } \\
\hline Health visitor or doctor advised me & 661 & Agree $^{*}$ & $39 \%(55)$ & $40 \%(196)$ & $43 \%(16)$ & 0.68 \\
\hline A book or leaflet suggested I should & 651 & Agree* & $12 \%(16)$ & $31 \%(146)$ & $43 \%(16)$ & $<0.001$ \\
\hline My family and friends told me to & 655 & Agree* & $40 \%(55)$ & $30 \%(146)$ & $25 \%(9)$ & 0.024 \\
\hline I thought it was the right time & 681 & Agree* & $99 \%(141)$ & $96 \%(481)$ & $90 \%(35)$ & 0.017 \\
\hline My baby seemed hungry & 678 & Agree $^{*}$ & $99 \%(140)$ & $92 \%(458)$ & $79 \%(31)$ & $<0.001$ \\
\hline $\begin{array}{l}\text { Has it been easy to wean your baby } \\
\text { onto solid food? }\end{array}$ & 700 & Easy† & $76 \%(107)$ & $71 \%(370)$ & $68 \%(28)$ & 0.24 \\
\hline I thought my baby started weaning & 704 & $\begin{array}{l}\text { Too early } \\
\text { Too late }\end{array}$ & $\begin{array}{l}9 \%(13) \\
1 \%(2)\end{array}$ & $\begin{array}{l}3 \%(18) \\
3 \%(13)\end{array}$ & $\begin{array}{l}2 \%(1) \\
5 \%(2)\end{array}$ & 0.005 \\
\hline
\end{tabular}


Table 5 Independent predictors of early and late weaning compared to weaning aged 3-4 months

\begin{tabular}{|c|c|c|c|c|c|}
\hline \multirow[b]{2}{*}{ Question } & \multirow[b]{2}{*}{ Response } & \multicolumn{2}{|c|}{ Early weaners (<13 wk) } & \multicolumn{2}{|c|}{ Late weaners (>17.3 wk) } \\
\hline & & OR & $\mathbf{p}$ & OR & $\mathbf{p}$ \\
\hline Deprivation markers & One or more versus none & 1.95 & 0.0013 & & \\
\hline My baby seemed hungry & Strongly agree versus rest & 4.1 & 0.055 & 0.33 & 0.01 \\
\hline Breast fed at $4 \mathrm{mth}$ & Yes versus no & 0.51 & 0.038 & 2.94 & 0.003 \\
\hline Number in model & 649 & & & & \\
\hline
\end{tabular}

All the variables that were individually predictive of either early or later weaning were put together into a logistic regression model, and non-significant variables removed successively in order of diminishing statistical significance. In the final model deprivation, weight gain to 6 weeks and not breast feeding at age 4 months remained significant predictors of early weaning, while agreeing with the statement my "baby was hungry" was of borderline significance. For later weaning, only continued breast feeding at age 4 months and disagreeing with the statement "my baby was hungry" remained significant (table 5).

Infants weaned before 3 months were significantly more likely to suffer diarrhoea and marginally more likely to have seen their GP between 6 weeks and 4 months, after adjustment for feeding mode and deprivation level, but no more likely to suffer other ailments (table 6). There was no influence of age at weaning on illness rates at any other ages; in particular, infants weaned after 4 months were no more likely to have episodes of diarrhoea between the ages of 4 and 8 months than those weaned earlier (data not shown).

\section{DISCUSSION}

This is the first study to simultaneously examine both social and biological correlates of age of weaning, while tracking the process of weaning in detail, using both questionnaires and weaning diaries. There was some attrition, most commonly in the most deprived families, but since the study took place in a relatively deprived urban borough, those remaining still had deprivation scores representative of the northern region. The proportion weaned before 3 months was comparable to recent UK data, although the proportion weaned before 4 months was even higher. ${ }^{2}$ The cohort also had lower rates of breast feeding than the UK as a whole.

The majority of mothers introduced solids between 3 and 4 months and were confident that this was the right time. Mothers who weaned before 3 months seemed aware that they were acting against recommendations, as few cited written or professional influences. The strongest perceived influence was that their baby was hungry. Rapid weight gain up to the age at weaning was also a strong predictor of early weaning and it seems likely that these babies did feed more avidly, which mothers interpreted as a need for solids. The tendency to early weaning in boys also seems to be a function of their larger size and therefore higher energy requirements and feeding drive. Age at weaning bore no relation to subsequent weight gain, which is well in keeping with recent trial evidence. ${ }^{18-20}$ This is important in view of the association between late weaning and failure to thrive observed previously, ${ }^{21}$ since this suggests that it is slow weight gain, probably associated with a relatively low drive to feed, that leads to late weaning, not the reverse.

It would be expected that mothers would experience greater difficulty weaning very young babies, but the diaries showed rapid progression with weaning, whenever it commenced. This suggests infants are ready to wean in oromotor terms well before 4 months. The majority of babies did not respond positively to their first taste of weaning solids, but by the fifth occasion, usually within five days of the first, most responded positively.

Babies weaned before 3 months had double the rates of parentally reported diarrhoea and were more likely to see their GP over the age period when solids were being introduced, compared to those weaned after 4 months. While some of the effect on GP consultations can be attributed to differences in deprivation and breast feeding rates, the increased rate of diarrhoea appeared largely independent of these effects. Other minor ailments, not expected to be affected by complementary feeding, did not differ by age of weaning. This makes it unlikely that this simply reflects a tendency for mothers who wean early to either over-report illness in their child or have differing views about what constitutes diarrhoea.

However this still could be a chance finding. The Dundee cohort study ${ }^{22}$ found no increase in gastrointestinal infections in those weaned before 12 weeks. In the two Honduras trials of age at weaning, one found slightly increased risks of diarrhoea in those weaned later, ${ }^{20}$ though the numbers were small and the prevalence of diarrhoea low. A large trial of

Table 6 Risk of parentally reported morbidity between age 6 weeks and 4 months, by age of weaning

\begin{tabular}{|c|c|c|c|c|c|c|c|c|}
\hline \multirow[b]{2}{*}{$\%$ (no.) aged 6 wk to $4 \mathrm{mth}$ who: } & \multicolumn{4}{|c|}{ Age of weaning } & \multicolumn{2}{|c|}{ Unadjusted } & \multicolumn{2}{|l|}{ Adjusted* } \\
\hline & Total no. & $<3 \mathrm{mth}$ & 3-4 mth & $>4 \mathrm{mth}$ & OR & p & OR $(95 \% \mathrm{Cl})$ & $\mathbf{p}$ \\
\hline Have seen GP & 658 & $65 \%(88)$ & $55 \%(268)$ & $44 \%(15)$ & 1.54 & 0.009 & $1.32(0.94$ to 1.89$) \dagger$ & 0.1 \\
\hline $\begin{array}{l}\text { Been admitted to hospital } \\
\text { Had episode of: }\end{array}$ & 659 & $10 \%(14)$ & $7 \%(34)$ & $9 \%(3)$ & & 0.34 & & \\
\hline Any diarrhoea & 615 & $31 \%(39)$ & $19 \%(87)$ & $14 \%(4)$ & 1.79 & 0.004 & $1.65(1.09$ to 2.5$) \ddagger$ & 0.02 \\
\hline Diarrhoea and saw GP & 615 & $18 \%(23)$ & $11.5 \%(53)$ & $11 \%(3)$ & 1.8 & 0.07 & & \\
\hline Cold & 644 & $70 \%(93)$ & $69 \%(330)$ & $66 \%(21)$ & & 0.67 & & \\
\hline Ear infection & 595 & $6 \%(7)$ & $6 \%(25)$ & $8 \%(2)$ & & 0.84 & & \\
\hline Rash & 605 & $32 \%(40)$ & $29 \%(132)$ & $23 \%(6)$ & & 0.36 & & \\
\hline Chest infection & 607 & $19 \%(24)$ & $15 \%(67)$ & $21 \%(6)$ & & 0.64 & & \\
\hline
\end{tabular}

*From logistic regression model including other significant predictors.

†Adjusted for deprivation and breast feeding aged 4 months.

$\ddagger$ Adjusted for breast feeding aged 4 months. 
promotion of exclusive breast feeding ${ }^{23}$ did find a significant reduction in gastrointestinal infections, but it was not possible to disaggregate the effects of age at weaning from those of breast feeding itself.

In conclusion, a majority of mothers introduced complimentary foods before the previously recommended age of 4 months and the important influences they recognised were the perceived needs of their baby, rather than external advice. The majority of infants progressed without difficulty to taking regular solids within a few days. However, even with the use of mainly processed weaning foods, early weaning seems to be associated with increased rates of diarrhoea over the weaning period.

\section{ACKNOWLEDGEMENTS}

Our thanks to Jayne Kelly, Anne Trail, Alison Smith, Jane Jarvis, and Ann Pattison for their work on the study, to Philip Lowe for computing support, to Victoria Blaylock for coding and entering the diary data, and to Lawrence Weaver and David Tappin for their comments on the manuscript. The study would not have been possible without the invaluable support of the midwives at the Gateshead and Newcastle maternity units, the health visitors of Gateshead, and the loyal participation of all the parents.

\section{Authors' affiliations}

C M Wright, Department of Child Health, University of Glasgow, UK K N Parkinson, Department of Child Health, University of Newcastle upon Tyne, UK

R F Drewett, Department of Psychology, University of Durham, UK

Grant support: Henry Smith Charity, SPARKS

\section{REFERENCES}

1 Foote KD, Marriott LD. Weaning of infants. Arch Dis Child 2003;88:488-92

2 Milla P. The weanling's gut. Acta Paediatr Scand Suppl 1986;323:5-13.

3 Kelly D, Phillips A, Elliott E, et al. Rise and fall of coeliac disease 1960-85. Arch Dis Child 1989;64:1157-60.

4 Fergusson D, Horwood L, Shannon F. Early solid feeding and recurrent childhood eczema: a 10-year longitudinal study. Pediatrics 1990;85:541-6.

5 Wilson A, Forsyth J, Greene S, et al. Relation of infant diet to childhood health: seven year follow up of cohort of children in Dundee infant feeding study. BMJ 1998;316:21-5.
6 Dewey KG, Peerson JM, Brown KH, et al. Growth of breast-fed infants deviates from current reference data: a pooled analysis of US, Canadian, and European data sets. World Health Organization Working Group on Infant Growth. Pediatrics 1995;96:495-503.

7 Whitehead R, Paul A, Ahmed E. Weaning practices in the United Kingdom and variations in anthropometric development. Acta Paediatr Scand 1986;323:14-23.

8 Paine $\mathbf{P}$, Spegiorin C. Prolonged breast feeding related to later solid food acceptance. Child Care Health Dev 1983;9:321-6.

9 Northstone K, Emmett P, Nethersole F, et al. The effect of age of introduction of too lumpy solids on foods eaten and reported feeding difficulties at 6 and 15 months. J Hum Nutr Dietet 2000;14:43-54.

10 Committee on Medical Aspects of Food. Weaning and the weaning diet. Health and social subjects. Department of Health, 45. London: HMSO, 1994

11 Department of Health. Infant feeding. London: Department of Health, 2003.

12 http://www.doh.gov.uk/infantfeeding/index.htm.

13 Hamlyn B, Brooker S, Oleinikova K, et al. Infant feeding 2000. Department of Health, 2003. http://www.doh.gov.uk/pdfs/infantreport2000.pdf.

14 Freeman JV, Cole TJ, Chinn S, et al. Cross sectional stature and weight reference curves for the UK, 1990. Arch Dis Child 1995;73:17-24.

15 Preece M, Freeman J, Cole T. Sex differences in weight in infancy: published centile charts have been updated. BMJ 1996;313:1486.

16 Wright CM, Waterston A, Matthews JNS, et al. What is the normal rate of weight gain in infancy? Acta Paediatr 1994;83:351-6.

17 Davey Smith G, Blane D, Bartley M. Explanations for socio-economic differentials in mortality. Evidence from Britain and elsewhere. Eur J Public Health 1994;4:131-44.

18 Townsend P, Phillimore P, Beattie A. Health and deprivation: inequality and the North. London: Croom Helm, 1988.

19 Mehta K, Specker B, Bartholmey S, et al. Trial on timing of introduction to solids and food type on infant growth. Pediatrics 1998;102:569-73.

20 Cohen R, Brown K, Canahuati J, et al. Effects of age of introduction of complementary foods on infant breast milk intake, total energy intake, and growth: a randomised intervention study in Honduras. Lancet 1994;343:288-93.

21 Dewey K, Cohen R, Brown K, et al. Age of introduction of complementary foods and growth of term, low-birth-weight, breast-fed infants: a randomized intervention study in Honduras. Am J Clin Nutr 1999;69:679-86.

22 Wright C, Loughridge J, Moore J. Failure to thrive in a population context: two contrasting case control studies of feeding and nutritional status. Proc Nutr Soc 2000:59:37-45.

23 Forsyth JS, Ogston SA, Clark A, et al. Relation between early introduction of solid food to infants and their weight and illnesses during the first two years of life. BMJ 1993;306:1572-6.

24 Kramer MS, Chalmers B, Hodnett ED, et al. Promotion of Breastfeeding Intervention Trial (PROBIT): a randomized trial in the Republic of Belarus. JAMA $2001 ; 285: 413-20$.

25 Fergusson D. Asthma and infant diet. Arch Dis Child 1983;58:48-51.

26 Kramer MS, Guo T, Platt RW, et al. Breastfeeding and infant growth: biology or bias? Pediatrics 2002;110:343-7.

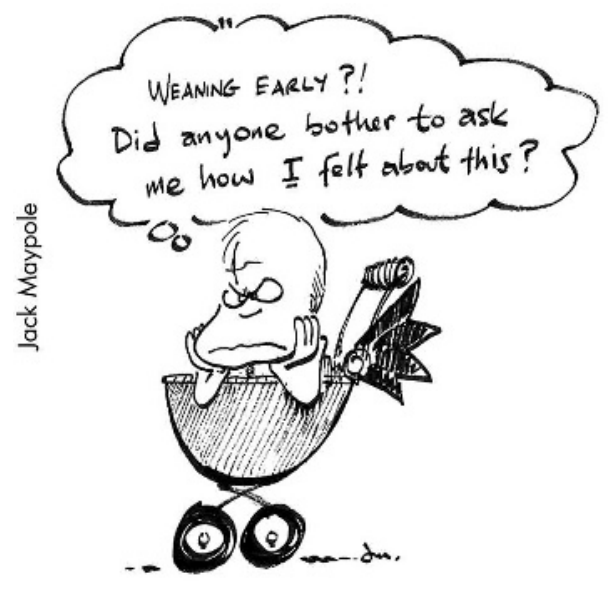

